\title{
Kinematic on Ankle and Knee Joint of Post-Stroke Elderly Patients by Wearing Newly Elastic Band-Type Ankle-Foot Orthosis in Gait
}

This article was published in the following Dove Press journal:

Clinical Interventions in Aging

\section{Jong Hyun Kim \\ Byeong Hee Won}

Biomedical System \& Technology Group, Korea Institute of Industrial Technology, Cheonan, Chungnam, South Korea
Correspondence: Byeong Hee Won Biomedical System \& Technology Group, Korea Institute of Industrial Technology, 89, Yangdaegiro-gil, Ipjang-myeon, Seobuk-gu, Cheonan-si,

Chungcheongnam-do 33I-822, South Korea

Tel +82-|0-373|-8090

$\mathrm{Fax}+82-505-73|-809|$

Email bhwon@kitech.re.kr
Purpose: The post-stroke elderly was increased caused by increasing stroke and advanced medical. However, ankle-foot orthoses (AFOs) can be uncomfortable for hemiplegic patients; therefore, the usability is not good. In this study, we analyzed ankle and knee joint angles in post-stroke elderly patients to assess the functional effectiveness (specifically prevention of back knee and drop-foot) of a new elastic band-type AFO (New Product: NP) during gait.

Patients and methods: Nine elderly post-stroke patients (eight males, one female; 55.7 \pm 8.4 years; $165.8 \pm 9.2 \mathrm{~cm} ; 68.8 \pm 11.5 \mathrm{~kg}$; five with right hemiplegia, four with left hemiplegia; onset period: 6.6 years) were selected for participation in this study. We captured gait motion using 12 cameras (MX-T20, Vicon, Inc., Oxford, UK) under three different conditions [wearing nothing (WI), using existing ordinary AFOs made from hard plastic material (EP), and using NP]. The angle variation and maximum-minimum angle of the lower body joints were analyzed during dorsi-plantar flexion of the ankle joint and flexion-extension of knee joint. A one-way ANOVA test for multiple comparisons was performed, followed by a Tukey's b test to identify statistical significance, which was set at 0.005 .

Results: Regarding the ankle joint, the maximum plantar flexion (drop-foot) value decreased with the NP, and the maximum dorsiflexion value increased. Regarding the knee joint, the maximum extension (back knee) value decreased, and the maximum flexion value increased $(\mathrm{p}<0.005)$.

Conclusion: Using analysis of the kinematics of the ankles and knees during walking, this research confirmed the effectiveness of the NP, an elastic band-type AFO, for use in ordinary post-stroke elderly patients.

Keywords: hemiplegia, gait motion, back knee, drop-foot, dorsiflexion, extension

\section{Introduction}

Increase in the aging population and the adoption of a westernized diet are leading to a rise in the incidence of stroke every year. ${ }^{1}$ The ability to walk independently around the home and in the community is important for people after stroke because it enables participation in social and domestic roles and promotes quality of life. ${ }^{2,3}$ Although it is estimated that $85 \%$ of people can walk independently 6 months post-stroke, ${ }^{2}$ only a small proportion achieve normative levels of walking ability. ${ }^{3-5}$ The quality of independent walking is also important. An independent gait of a possible social participant level should be able to overcome barriers and slopes to the appropriate speed. Therefore, several studies ${ }^{3-6}$ have focused on developing a method for evaluating the 
quality of gait and the level of independent gait capacity, with other studies ${ }^{4-6}$ focusing on improvement and optimization of gait. More than $40 \%$ of the previous studies emphasize the importance of the knee and ankle function for gait. ${ }^{7-9}$ In addition, some studies validated the effectiveness of anklefoot orthoses (AFOs) for improving the stability of the knee and ankle during gait. ${ }^{7-9}$ Hence, many independent ambulant hemiplegic patients use AFOs. ${ }^{8-12}$

Hemiparesis due to stroke often results in spastic dropfoot, ${ }^{13,14}$ which is the loss of ability to perform dorsiflexion of the foot on the affected side. ${ }^{14-16}$ The management of spastic drop-foot is the prescription of an AFO, which is designed to provide ankle stability during stance and adequate toe clearance during swing and to promote heel strike. $^{15,16}$ In previous studies, cases with and without AFOs have been compared, ${ }^{18,19}$ while in some studies, different types of AFOs have been analyzed. ${ }^{20,21}$ Most of the studies performed thus far have focused on the kinematic study of the ankles ${ }^{22,23}$ or have evaluated the effectiveness of AFOs using a systematic approach. ${ }^{24}$ However, recently, studies have adopted a kinematic approach that assesses the interrelation between the ankles and knees. $^{25,26}$ These studies show that the use of AFOs increases knee flexion ${ }^{25}$ and that excessive plantar flexion resistance causes a reduction in knee flexion. ${ }^{25,27}$

Therefore, the ideal aim of an AFO is to realize appropriate ankle plantar flexion resistance, leading to dorsiflexion, and thereby an increase in knee flexion. However, most of the commonly used AFOs are made of plastic, and hence, they have low wearability and are uncomfortable to use. Hence, the demand for soft AFOs is increasing. Soft AFOs provide good wearing sensation, are convenient to wear, and are in more direct contact with the feet than the plastic AFOs. ${ }^{17}$ Further, owing to their material characteristics, the existing plastic AFOs probably restrict both dorsiflexion and plantar flexion excessively, thereby reducing knee flexion. ${ }^{25,27}$ Therefore, research has focused on developing elastic band-type AFOs made of elastic materials to make wearing an AFO convenient and more comfortable. Further, other studies have proven that elastic band-type AFOs (New Product: NP, elastic band-type AFOs) ${ }^{28,29}$ are effective in preventing drop-foot by achieving appropriate plantar flexion resistance of the ankles and realizing plasticity in plantar-dorsiflexion in hemiplegia patients.

In this study, to analyze the effectiveness of the NP, gait analysis was conducted under three different conditions: with the NP, with the existing product made of hard plastic material (Existing ordinary Product: EP, AFOs made of hard plastic material), and without any AFO (WI, Wearing nothing). The gait analysis was conducted via a kinematic analysis of knee flexion and plantar-dorsiflexion under the three abovementioned conditions.

\section{Materials and Methods Subjects}

This study received approval from the Public IRB designated by the Ministry of Health \& Welfare, South Korea, for the experimental plan and procedures to conduct experiments on subjects suffering hemiplegia as an aftereffect of stroke. In addition, this study was conducted in accordance with the Helsinki Declaration, established the experimental plan, explained the procedures and interests of the study to the participants, and completed the participation agreement document. To identify hemiplegia patients who could walk, we formed an advisory committee comprised mostly of experts from the National Rehabilitation Center to contact potential subjects. We contacted the subjects selected by the committee. All subjects had sufficient understanding of the experiment and agreed to participate in the experiment by signing documents detailing the scope and procedures of the experiment, the imaging, and the academic use of the results before they participated in it. The experiment was conducted at the laboratory of the UETC (Usability Evaluation Technology Center, Korea Institute of Industrial Technology) at the Seongnam Senior Experience Complex from August to October 2014.

Several limitations were laid down for selecting the subjects in order to ensure reliability of the results of the gait experiment. The subjects were required to be able to walk at least $10 \mathrm{~m}$ independently. Any hemiplegia patient whose walking speed was $\leq 0.2 \mathrm{~m} / \mathrm{s}$ or $\geq 0.8 \mathrm{~m} / \mathrm{s}$ was excluded. In addition, patients with chronic cardiac failure, diabetes, or hypertension were excluded. One (subject 1) of the 10 subjects did not satisfy the selection criteria (walking speed: $0.2 \mathrm{~m} / \mathrm{s}$ or less) and was not selected for the analysis. Hence, the experiment results of the remaining nine subjects were analyzed.

The height $(165.8 \pm 9.2 \mathrm{~cm})$ and weight $(68.8 \pm 11.5 \mathrm{~kg})$ of the subjects were measured, and other information were collected through interviews: age (55.7 \pm 8.43 years $)$, gender, affected side, the time of onset of hemiplegia, whether the AFO was worn daily, whether they had experienced falls, and the stroke type (Table 1).

\section{Measurement of Data}

The EP, whose effectiveness was compared with that of the NP, was chosen according to certain criteria. A commonly 
Table I Subject Characteristics

\begin{tabular}{|c|c|c|c|c|c|c|}
\hline Participants & Sex & $\begin{array}{l}\text { Time Since Stroke } \\
\text { (Months) }\end{array}$ & Daily Use of AFOs & Paretic Side & $\begin{array}{l}\text { Positive History of } \\
\text { Falls (Yes/No) }\end{array}$ & Type of Stroke \\
\hline I & $M$ & 80 & No & Right & $\mathrm{N}$ & Ischemic \\
\hline 2 & $M$ & 130 & No & Right & $Y$ & Ischemic \\
\hline 3 & $\mathrm{~F}$ & 12 & No & Right & $Y$ & Hemorrhagic \\
\hline 4 & $M$ & 72 & Partially & Right & $\mathrm{N}$ & Ischemic \\
\hline 5 & $M$ & 82 & No & Right & $Y$ & Ischemic \\
\hline 6 & M & 129 & No & Left & $Y$ & Ischemic \\
\hline 7 & $M$ & 115 & No & Left & $Y$ & Ischemic \\
\hline 8 & $M$ & 60 & Partially & Left & $\mathrm{N}$ & Hemorrhagic \\
\hline 9 & $M$ & 24 & Constantly & Left & $\mathrm{N}$ & Hemorrhagic \\
\hline 10 & $M$ & 72 & Constantly & Left & $\mathrm{N}$ & Hemorrhagic \\
\hline
\end{tabular}

used AFO (Figure 1) was chosen from among the plastic AFOs that are similar to the NP in terms of their shapes and those that could be worn in shoes. In addition, these AFOs have open heels, they permit sensation inputs, and they have a shape that assists only the ankles.

During the experiment, the subjects kept their house shoes on. Each subject walked $6 \mathrm{~m}$ one way (Figure 2) with house shoes on, while wearing no AFO (WI), while wearing an NP (Figure 1A), and while wearing an EP (Figure 1B).

The 3D motion capture for gait analysis was performed using a Plug-In Gait full body marker set. A total of 35 reflector markers (Figure 2) were attached on the subjects' bodies. Twelve MX-T20 cameras (Vicon Inc., Oxford, UK) captured the motions at a frame rate of $100 \mathrm{~Hz}$.

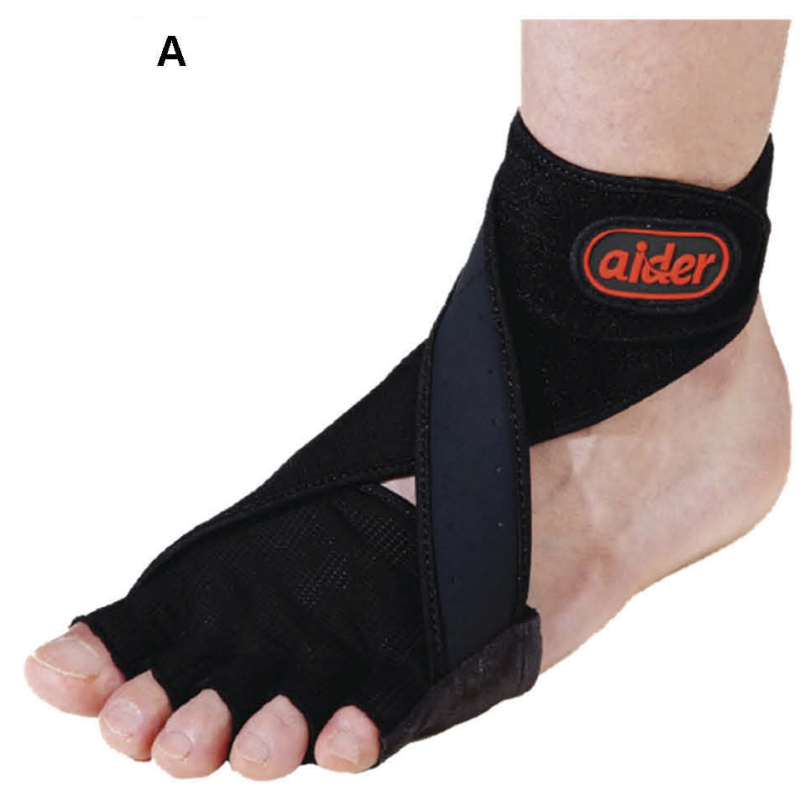

\section{Data Analysis}

Gait data were derived by dividing walking into cycles based on a strike-strike motion, ie, the heel marker of the affected side touching the ground and then touching it again (Figure 2). During gait cycle stance, the knee extension (back knee) was analyzed primarily, as well as the swing of the gait cycle and ankle plantar-dorsiflexion (drop-foot).

To conduct a reliable gait analysis, the subjects performed at least three gait cycles under each condition.

The analysis was performed for the range of the angles at the ankles and knees, and the maximum ankle dorsiflexion, plantar flexion, knee flexion, and extension values were obtained (Figure 3).

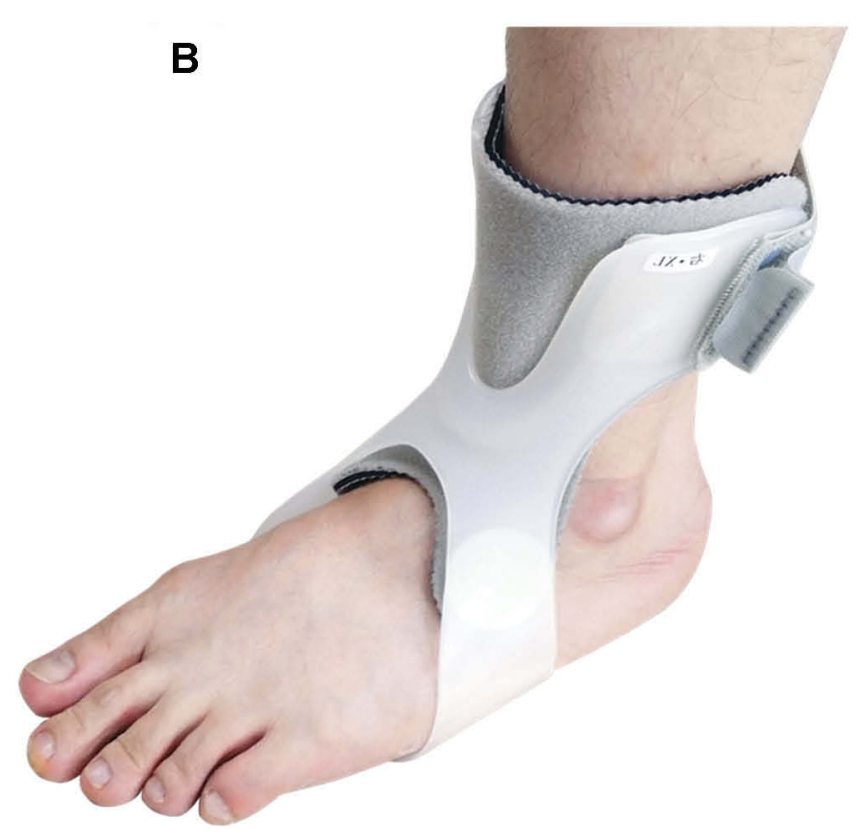

Figure I Ankle-foot orthosis (AFO) types: (A) elastic band-type AFO, (B) hard plastic material-type AFO. 

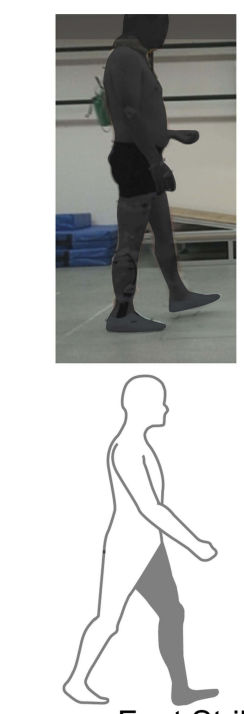

Foot Strike

$\%$ of

Cycle $0 \%$
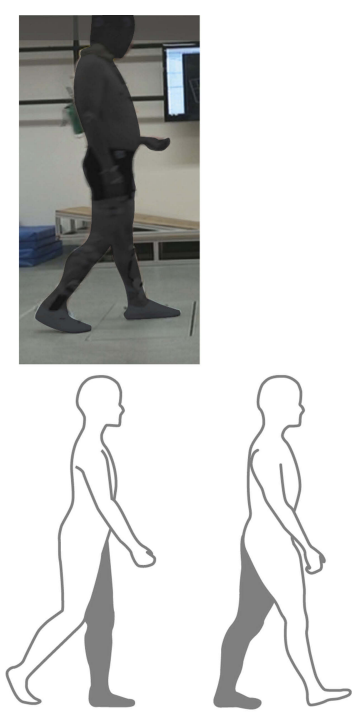

Stance
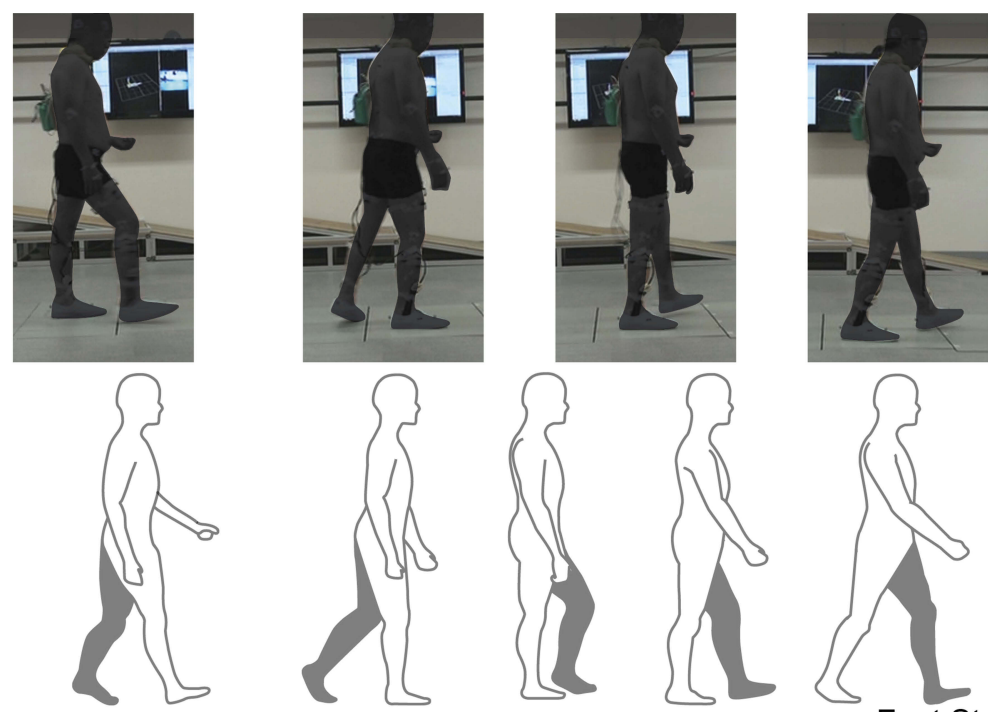

Foot Strike

$62 \%$

$100 \%$

Figure 2 The gait experiment of the hemiplegic patient, one gait cycle = foot strike-strike (affected side).

ANOVA analysis (post examination: Tukey's b) was performed to check whether the differences in averages were significant $(\mathrm{p}<0.005)$ because there were three independent variables (WI, NP, and EP) affecting four dependent variables (the maximum angles of the ankles [dorsiflexion, plantar flexion] and the maximum angles of the knees [flexion, extension]).

To determine the correlation between ankle plantardorsiflexion and knee flexion-extension, a correlation analysis (Pearson's correlation coefficient) was performed between the four dependent variables.

\section{Results}

The knee and ankle joint angle variables in the gait cycle showed similar trends for all three types. During stance of the affected side, the maximum knee extension and ankle dorsiflexion were revealed, whereas during swing, the maximum knee flexion and plantar flexion were revealed.

\section{The Ankle Angle Range}

During dorsiflexion, the maximum angle was $10.51^{\circ}$ $\left( \pm 5.31^{\circ}\right)$ in the NP condition, followed by $9.45^{\circ}\left( \pm 6.39^{\circ}\right)$ for WI and $6.84^{\circ}\left( \pm 6.22^{\circ}\right)$ for EP. The results of dorsiflexion showed significant differences between all conditions $(\mathrm{p}<0.005$; Figure $4 \mathrm{~A})$.

In contrast, during plantar flexion, the maximum angle was $7.12^{\circ}\left( \pm 7.35^{\circ}\right)$ in the EP condition, followed by $5.03^{\circ}$ $\left( \pm 9.32^{\circ}\right)$ for WI and $1.77^{\circ}\left( \pm 8.17^{\circ}\right)$ for NP. The results of plantar flexion also showed significant differences between all conditions ( $\mathrm{p}<0.005$; Figure 4A).

\section{The Knee Angle Range}

During flexion, the maximum angle was $18.51^{\circ}\left( \pm 8.28^{\circ}\right)$ in the NP condition, followed by $16.14^{\circ}\left( \pm 10.03^{\circ}\right)$ for EP and $15.28^{\circ}\left( \pm 8.60^{\circ}\right)$ for WI. Significant differences $(\mathrm{p}<0.005)$ were found between the NP condition and the other conditions, but no significant difference $(\mathrm{p}=0.194)$ was found between WI and EP (Figure 4B).

During extension, the maximum angle was $7.30^{\circ}$ $\left( \pm 11.48^{\circ}\right)$ in the EP condition, followed by $7.11^{\circ}\left( \pm 10.95^{\circ}\right)$ for WI and $2.99^{\circ}\left( \pm 10.66^{\circ}\right)$ for NP. Significant differences $(p<0.005)$ were found between the NP and other conditions, but no significant difference $(\mathrm{p}=0.832)$ was found between WI and EP conditions (Figure 4B).

\section{Correlation Analysis}

The correlation analysis showed a strong negative correlation between the opposite movements (plantar-dorsiflexion and flexion-extension), a high positive correlation (correlation coefficient: $0.669^{* *}$ ) between ankle dorsiflexion and knee flexion, a high negative correlation (correlation coefficient: $-0.682 * *)$ between ankle dorsiflexion and knee extension, a low negative correlation (correlation coefficient: $\left.-0.386^{* *}\right)$ between ankle plantar flexion and knee flexion, and a moderate positive correlation (correlation 

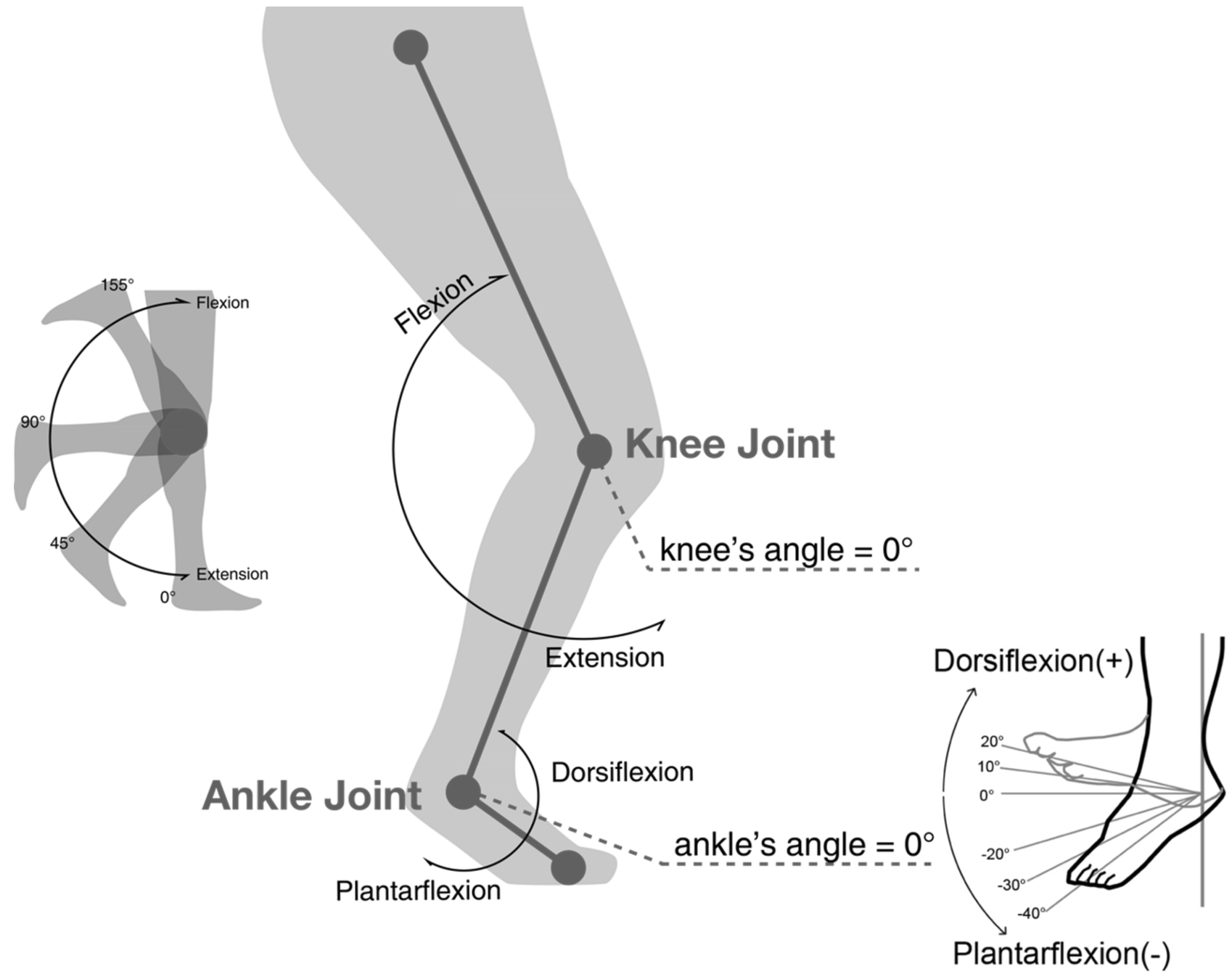

Figure 3 Definition of the knee and ankle joint angles.

coefficient: $0.484^{* *}$ ) between ankle plantar flexion and knee extension (Table 2).

\section{Discussion}

Our research showed that the NP can prevent drop-foot during walking in hemiplegia patients. They are more convenient to use than the existing AFOs, and they provide better wearing sensation.

In this research, the gait analysis for hemiplegia patients was conducted under three different conditions. Kinematic analysis was performed for the ankles and knees to evaluate the effectiveness of the NP. During the kinematic analysis performed during walking, the maximum ankle dorsiflexion value increased and the maximum ankle plantar flexion value decreased. From these results, we could confirm the preventive effect of the NP on dropfoot.
Further, based on the correlation between AFOs and the knee joints, as reported in previous studies, ${ }^{25,26}$ we confirmed the positive effect of the NP on the knee joint. In addition, in hemiplegia patients, the extension is $0^{\circ}$ or more because of the back-knee phenomenon that occurs when they walk, and this phenomenon is caused by muscle rigidity. Therefore, in this research, the effectiveness of AFOs for the knees was evaluated based on the maximum angle of flexion-extension. ${ }^{25,26}$ Based on the results of the evaluation, we confirmed that the use of the NP increases the maximum knee flexion and decreases the maximum knee extension. ${ }^{25}$ In addition, this result can be attributed to the fact that owing to its material characteristics, the NP does not resist the angular change at the ankle excessively. Moreover, considering that the subjects in this experiment could walk independently and that more than 6 years $(77.3$ months), which is a sufficiently long period for them to be 
A Ankle angle range(maximum): Dorsi-Plantar Flexion

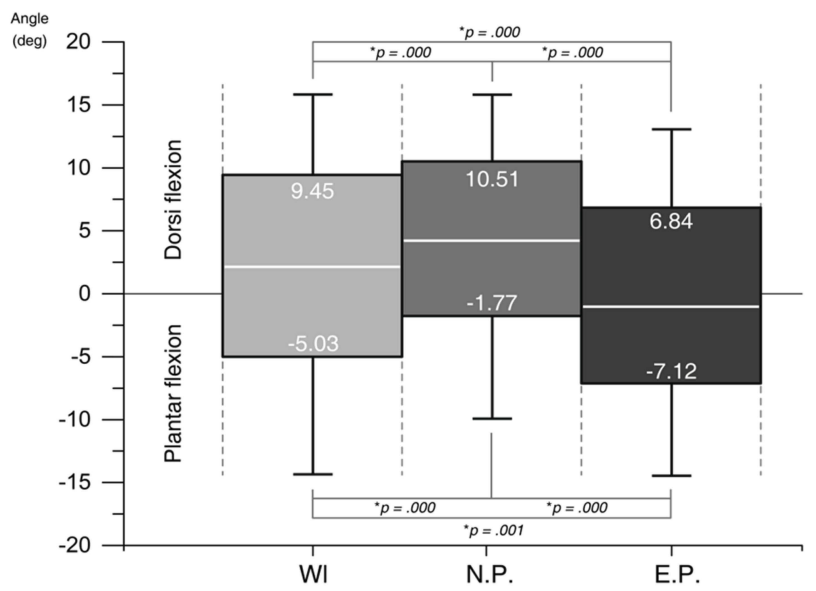

B Knee angle range(maximum): Flexion-Extension

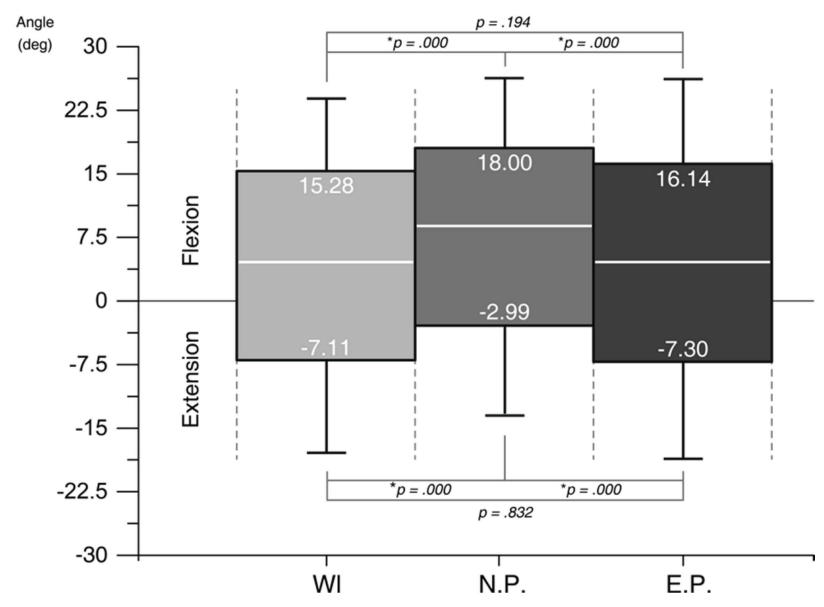

Figure $4 \mathrm{~A}$ comparison of ankle and knee joint kinematics and three conditions (WI, NP, and EP). (A) Ankle angle range in dorsiflexion and plantar flexion; and (B) knee angle range in flexion-extension.

Notes: In the result graph, the Y-axis represents the joint angle of the ankle and the knee, $(+)$ area is dorsiflexion of the ankle, flexion of the knee, $(-)$ area is plantar flexion of the ankle, extension of knee, and the white line in the box represents the mean value of the moving range. An asterisk (*) indicates a significant level of $p<0.005$.

Abbreviations: AFO, ankle-foot orthosis; WI, wearing nothing; NP, wearing elastic band-type AFO; EP, wearing hard plastic-type AFO

accustomed to walking, had passed since the onset of their disease, we found that the NP showed better effects than the EP. The NP ensures the angular elasticity of the ankles, thus yielding positive effects. This viewpoint is similar to the results of Toshiki's research, which showed that "excessive resistance to plantar flexion rather restricts knee flexion". 25 It also agrees with Marcelo's research, which reported that "[a]n appropriate use of AFO leads to increases in knee's flexion". ${ }^{26}$ Furthermore, based on the results of this experiment, we can understand why the EP yielded low effects. The angular variations at the ankles when using the EP (range: dorsiflexion-plantar flexion) were smaller than those when using the WI. This result is attributed to the excessive restriction imposed by the plastic material on the ankles, thus restricting dorsiflexion, which is a positive effect. Further, as reported by Toshiki, excessive angular restriction on the ankles is considered the cause of ineffectiveness of the EP during knee flexion-extension.

In this research, a correlation analysis was conducted for four dependent variables (ankle dorsiflexion, ankle plantar flexion, knee flexion, and knee extension) using Pearson's correlation coefficient. The results of the correlation analysis showed strong negative correlations between opposite movements. As ankle dorsiflexion increased, the ankle's plantar flexion decreased. This shows that negative correlation was maintained, while the range of angular changes did not change much. Similarly, in the case of the knee joint, as flexion increased, extension decreased. This represents a negative correlation between opposite movements. In other words, as ankle dorsiflexion and knee flexion-ie, the positive phenomena-increase, ankle plantar flexion (drop-foot) and knee extension (back knee) - ie, the negative phenomena-decrease.

Further, the correlation between the ankle and knee could be determined based on the results of the correlation analysis. In particular, ankle dorsiflexion and "knee joint flexion $\left(0.669^{* *}\right)$-extension $(-0.682 * *)$ " showed a highlevel correlation. Similar to the abovementioned analysis results, the correlation analysis showed that the positive effects of AFOs on the ankles include a reduction in the occurrence of the back-knee phenomenon and increased knee flexion.

This study had some limitations. The study was performed with hemiplegia patients who were accustomed to some degree of walking. Therefore, our results cannot be generalized to all hemiplegia patients, and NPs may not be better for all patients.

\section{Conclusions}

The kinematic analysis of the ankles and knee joints in this research confirmed that the elastic band-type AFO (NP) was effective in reducing the occurrence of drop-foot and the back-knee phenomena. Many hemiplegia patients and rehabilitation therapists who use AFOs believe that increasing resistance with the use of AFOs made of plastic or similar hard materials will be effective in preventing drop-foot. Hence, even the patients who were already accustomed to walking continued to use AFOs made of hard materials despite the discomfort. However, it has 
Table 2 Correlation Between Four Dependent Variables by Pearson's Correlation Coefficient

\begin{tabular}{|l|l|l|l|l|l|}
\hline & & Ankle D & Ankle P & Knee F & Knee E \\
\hline \multirow{2}{*}{ Ankle D } & P-correlation coefficient & - & $-0.859^{* *}$ & $0.669 * *$ & $-0.682^{* *}$ \\
\cline { 2 - 6 } & P-value & - & 0.000 & 0.000 & 0.000 \\
\hline \multirow{2}{*}{ Ankle P } & P-correlation coefficient & - & - & $-0.386 * *$ & $0.484^{* *}$ \\
\cline { 2 - 6 } & P-value & - & - & - & 0.000 \\
\hline \multirow{2}{*}{ Knee F } & P-correlation coefficient & - & - & - & -0.000 \\
\cline { 2 - 6 } & P-value & - & - & 0.000 \\
\hline
\end{tabular}

Notes: P-correlation: Pearson's correlation coefficient. An asterisk $(* *)$ indicates a significant level of $\mathrm{p}<0.0 \mathrm{I}$.

Abbreviations: D, dorsiflexion; P, plantar flexion; F, flexion; E, extension.

been proven that the NP, which was developed to overcome the issues of traditional AFOs, is more effective than an existing AFO (EP) in improving drop-foot, increasing knee flexion, and reducing the occurrence of the back-knee phenomenon.

The results of the effectiveness evaluation performed in this study are consistent with those of the preceding research. Previous researchers have claimed that elastic AFOs can have more positive effects on the ankles and knees.

When AFOs are chosen, different conditions, including the patient's health and walking ability, should be considered. This study confirmed that the soft material (fabric) used in the elastic band-type AFO was no less effective than the plastic material. Thus, we hope to inform hemiplegia patients and medical personnel of the results of this research of our finding.

\section{Acknowledgments}

This study was supported by the Korea Institute of Industrial Technology. A study of postural stability ${ }^{30}$ with the same subjects was published in the journal 'Clinical Interventions in Aging'.

\section{Disclosure}

The authors report no conflicts of interest in this work.

\section{References}

1. MK Business News (South Korea). The cumulative of stroke patients and onset number of stroke in Korea. 2011 April 12.

2. Cohen JW, Ivanova TD, Brouwer B, et al. Do performance measures of strength, balance, and mobility predict quality of life and community reintegration after stroke? Arch Phys Med Rehabil. 2018;99:713-719. doi:10.1016/j.apmr.2017.12.007

3. Datta Gupta A, Chu WH, Howell S, et al. A systematic review: efficacy of botulinum toxin in walking and quality of life in post-stroke lower limb spasticity. Syst Rev. 2018;7:1-9. doi:10.1186/s13643-017-0670-9
4. Springer S, Friedman I, Ohry A. Thoracopelvic assisted movement training to improve gait and balance in elderly at risk of falling: a case series. Clin Interv Aging. 2018;13:1143-1149. doi:10.2147/ CIA

5. Ahn BR, Kang HJ, Choi EJ, et al. Correlation of the Korean version of falls efficacy scale-international with quantitative balance and gait parameters through exercise program in elderly men. Ann Rehabil Med. 2019;43:195-203. doi:10.5535/arm.2019.43.2.195

6. Begg R, Galea MP, James L, et al. Real-time foot clearance biofeedback to assist gait rehabilitation following stroke: a randomized controlled trial protocol. Trials. 2019;20:317. doi:10.1186/s13063019-3404-6

7. Saleh MS, Rehab NI. Effect of ankle proprioceptive training on gait and risk of fall in patients with diabetic neuropathy: a randomized controlled trial. Int J Diabetes Res. 2019;2:40-45.

8. Petersen W, Ellermann A, Henning J, et al. Non-operative treatment of unicompartmental osteoarthritis of the knee: a prospective randomized trial with two different braces-ankle-foot orthosis versus knee unloader brace. Arch Orthop Trauma Surg. 2019;139:155-166. doi:10.1007/s00402-018-3040-8

9. Qiao M, Feld JA, Franz JR. Aging effects on leg joint variability during walking with balance perturbations. Gait Posture. 2018;62:27-33. doi:10.1016/j.gaitpost.2018.02.020

10. Buckon CE, Thomas SS, Jackobson-Huston S, Sussman M, Aiona M. Comparison of three ankle-foot orthosis configurations for children with spastic hemiplegia. Dev Med Child Neurol. 2001;43:371-378. doi:10.1017/S0012162201000706

11. Wang C, Goel R, Rahemi H, et al. Effectiveness of daily use of bilateral custom-made ankle-foot orthoses on balance, fear of falling and physical activity in older adults: a randomized controlled trial. Gerontology. 2019;65:299-307. doi:10.1159/000494114

12. Taiar R, Adel C, Belassian G, et al. Can a new ergonomical anklefoot orthosis (AFO) device improve patients' daily life? A preliminary study. Theor Issues Ergonom Sci. 2019. doi:10.1080/ 1463922X.2019.1616332

13. Lee S-H, Choi C, Lee D, et al. A novel hinged ankle foot orthosis for gait performance in chronic hemiplegic stroke survivors: a feasibility study. Biomed Eng Lett. 2018;8:301-308. doi:10.1007/s13534-018-0074-3

14. Sheng Y, Kan S, Wen Z, et al. Effect of kinesio taping on the walking ability of patients with foot drop after stroke. Evid Based Complement Alternat Med. 2019:2459852. doi:10.1155/2019/2459852

15. Liu Y, Zang X, Zhang N. Design and evaluation of a wearable powered foot orthosis with metatarsophalangeal joint. Appl Bionics Biomech. 2018;9289505. doi:10.1155/2018/9289505

16. Yeung LF, Ockenfeld C, Pang MK, et al. Randomized controlled trial of robot-assisted gait training with dorsiflexion assistance on chronic stroke patients wearing ankle-foot-orthosis. J Neuroeng Rehabil. 2018;15:51. doi:10.1186/s12984-018-0394-7 
17. Kim JH, Sim WS, Lim SY, Won BH. Analysis of lower-body-joint angle in hemiplegic patients wearing new elastic-band-type ankle-foot orthosis while walking. Asian Conf Ergon Des. 2014;5:901-904.

18. Kobayashi T, Leung AK, Akazawa Y, Hutchins SW. Effect of ankle-foot orthoses on the sagittal plane displacement of the center of mass in patients with stroke hemiplegia: a pilot study. Top Stroke Rehabil. 2012;19:338-344. doi:10.1310/tsr1904-338

19. Danielsson A, Sunnerhagen KS. Energy expenditure in stroke subjects walking with a carbon composite ankle foot orthosis. $J$ Rehabil Med. 2004;36:165-168. doi:10.1080/16501970410025126

20. Ohsawa S, Ikeda S, Tanaka S, et al. A new model of plastic ankle foot orthosis (FAFO (II)) against spastic foot and genu recurvatum. Prosthet Orthot Int. 1992;16:104-108. doi:10.3109/03093649209164320

21. Hachisuka K, Ogata H, Tajima F, Ohmine S. Clinical evaluations of dorsiflexion assist controlled by spring ankle-foot orthosis for hemiplegic patients. J UOEH. 1998;20:1-9. doi:10.7888/juoeh.20.1

22. Chen CC, Hong WH, Wang CM, et al. Kinematic features of rear-foot motion using anterior and posterior ankle-foot orthoses in stroke patients with hemiplegic gait. Arch Phys Med Rehabil. 2010;91:1862-1868. doi:10.1016/j.apmr.2010.09.013

23. Bleyenheuft C, Deltombe T, Detrembleur C. Influence of ankle-foot orthoses on kinematic segmental covariation among stroke patients. Ann Phys Rehabil Med. 2013;56:3-13. doi:10.1016/j.rehab.2012.11.001
24. Yamamoto S, Miyazaki S, Kubota T. Quantification of the effect of the mechanical property of ankle-foot orthoses on hemiplegic gait. Gait Posture. 1993;1:27-34. doi:10.1016/0966-6362(93)90040-8

25. Kobayashi T, Leung AK, Akazawa Y, Hutchins SW. The effect of varying the plantarflexion resistance of an ankle-foot orthosis on knee joint kinematics in patients with stroke. Gait Posture. 2013;37:457-459. doi:10.1016/j.gaitpost.2012.07.028

26. Gatti MA, Freixes O, Fernandez SA, et al. Effects of ankle foot orthosis in stiff knee gait in adults with hemiplegia. J Biomech. 2012;45:2658-2661. doi:10.1016/j.jbiomech.2012.08.015

27. Perry J. Gait and Analysis: Normal and Pathological Function. Thorofare, NJ: Slack Inc.; 1992.

28. Boudarham J, Roche N, Pradon D, Bonnyaud C, Bennsmail D, Zory R. Variations in kinematics during clinical gait analysis in stroke patients. PLoS One. 2013;8:e66421. doi:10.1371/journal.pone.0066421

29. Nolan KJ, Savalia KK, Yarossi M, Elovic EP. Evaluation of a dynamic ankle foot orthosis in hemiplegic gait: a case report. NeuroRehabilitation. 2010;27:343-350. doi:10.3233/NRE-2010-0618

30. Kim JH, Sim WS, Won BH. Effectiveness of elastic band-type ankle-foot orthoses on postural control in poststroke elderly patients as determined using combined measurement of the stability index and body weight-bearing ratio. Clin Interv Aging. 2015;10:1839-1847. doi:10.2147/CIA.S92888
Clinical Interventions in Aging

\section{Publish your work in this journal}

Clinical Interventions in Aging is an international, peer-reviewed journal focusing on evidence-based reports on the value or lack thereof of treatments intended to prevent or delay the onset of maladaptive correlates of aging in human beings. This journal is indexed on PubMed Central, MedLine, CAS, Scopus and the Elsevier

\section{Dovepress}

Bibliographic databases. The manuscript management system is completely online and includes a very quick and fair peer-review system, which is all easy to use. Visit http://www.dovepress.com/ testimonials.php to read real quotes from published authors. 